\title{
Reactions of Aromatic Fluorocarbons with Hydrogen ${ }^{12}$
}

\author{
Roland E. Florin, Walter J. Pummer, and Leo A. Wall
}

\begin{abstract}
Various palladium and platinum catalysts were used to effect the following hydrogenation reactions at relatively high conversions and yields:

$$
\begin{aligned}
& \mathrm{C}_{6} \mathrm{~F}_{4} \mathrm{ClH} \stackrel{\mathrm{Pd}}{280^{\circ}} \mathrm{C}_{6} \mathrm{~F}_{4} \mathrm{H}_{2} \\
& \mathrm{C}_{6} \mathrm{~F}_{4} \mathrm{ClCF}_{3} \stackrel{\mathrm{Pd}}{280^{\circ}} \mathrm{C}_{6} \mathrm{~F}_{4} \mathrm{HCF}_{3} \\
& \mathrm{C}_{6} \mathrm{~F}_{6} \underset{300^{\circ}}{\stackrel{\mathrm{Pt}}{\longrightarrow}} \mathrm{C}_{6} \mathrm{~F}_{5} \mathrm{H}, \mathrm{C}_{6} \mathrm{~F}_{4} \mathrm{H}_{2}
\end{aligned}
$$

Nickel could be used for some of the reactions, but with much greater difficulty. The products of these reactions can be iodinated and brominated, and hence are a starting point for the synthesis of many new derivatives of aromatic fluorocarbons.
\end{abstract}

\section{Introduction}

Derivatives of aromatic fluorocarbons with one and two reactive functional groups are desirable for the synthesis of high-temperature-resistant polymers. The mono- and dihydro-derivatives, e.g., pentafluorobenzene and tetrafluorobenzene, can be readily brominated and iodinated to form iodopentafluorobenzene and diiodotetrafluorobenzene, which are desirable starting substances for further syntheses.

It has now been found possible to prepare the requisite hydrogen compounds by a high-temperature hydrogenation of the more readily available perfluoro and chlorofluoro aromatics. Many common procedures for hydrogenation, when applied to haloaromatics, encounter difficulty due to catalyst poisoning; others often lead to saturation of the molecule to form the cyclohexane ring. However, nickel at high temperatures and atmospheric pressure will remove chlorine without becoming poisoned and without saturating the ring $[1] ;^{3}$ more recently it has been found that molybdenum disulfide at about $500^{\circ} \mathrm{C}$ can act likewise [2].

When Swarts [3] tried to use nickel at $270^{\circ} \mathrm{C}$ for the hydrogenation of fluorobenzene he was unable to proceed because of rapid poisoning of the catalyst. Low-temperature hydrogenation upon platinum was very rapid, as the catalyst was immune to poisoning by hydrogen fluoride or silicon tetrafluoride. Unfortunately, fluorobenzene formed cyclohexane exclusively without a trace of benzene.

\section{Results and Discussion}

The present procedure is essentially a Sabatier method, but employs various catalysts. It was found possible to use nickel in the reduction of chloropentafluorobenzene, chlorotetrafluorobenzene, and chloroheptafluorotoluene to produce moderate yields of

${ }^{1}$ Presented as part of the Symposium on Fluorine Chemistry, Division of Industrial and Engineering Chemistry, at the 134th Meeting of the American Chemical Society, Chicago, Ill., September 1958.

2 This work was performed as part of a research project sponsored by the Bureau of A eronautics, Department of the Navy, Washington 25, D.C.

${ }_{3}^{3}$ Figures in brackets indicate the literature references at the end of this paper. tetrafluorobenzene and heptafluorotoluene, but low activity and fairly rapid poisoning made the operation difficult. The most useful form of nickel appeared to be a thin layer of powder along the bottom of the furnace tube. The relative amounts of chloride and fluoride liberated varied with the type and age of the nickel catalyst. Spent catalyst could be regenerated partially by passage of water vapor, but the restored activity did not last long. The distillation behavior of both the trerafluorobenzene and the heptafluorotoluene suggests the presence of several isomers.

By contrast, catalysts of palladium on carbon and platinum on carbon were efficient and durable, permitting many successive runs and high conversions per pass. Palladium was highly selective for chlorine removal at $280^{\circ} \mathrm{C}$. At $300^{\circ} \mathrm{C}$ and in the presence of moisture it also effected the removal of fluorine from hexafluorobenzene, but soon lost its activity, possibly by sintering. Platinum at $300^{\circ} \mathrm{C}$ removed fluorine from hexafluorobenzene, and retained its activity for long times. The yield of monohydro derivative was high. At 17 percent conversion of hexafluorobenzene over palladium, the distribution of products was 40 percent pentafluorobenzene, 10 percent tetrafluorobenzenes, and 4 percent trifluorobenzenes. Product distributions using platinum catalyst at conversions up to 58 percent appear roughly similar. The large proportions of monohydro derivatives seem contrary to the implications of classical work on other polyhalogenated benzenes [1], for which it is stated that the fewer the remaining halogens, the more easily the reduction proceeds.

A few further points call for brief discussion. (1) The importance of high temperatures for substitution without saturation has an obvious, though not strictly necessary, connection with the benzenecyclohexane equilibrium, which becomes rather favorable to benzene around $300^{\circ}$ C. (2) The reason for the selectivity of palladium for chlorine is obscure. Possibly in the surface-activated complex the palladium has a preferential attraction for the 
chlorine atom, weakening the carbon-chlorine bond. The neighboring element, silver, appears to have a strong affinity for chlorine relative to fluorine, as indicated by solubilities of the halides [4]. (3) Hydrogenation attacks the ring halogen and leaves the trifluoromethyl group untouched, while the reverse is true for hydrolysis over alumina [5].

It is tempting to extend as far as possible the familiar classifications of solution chemistry. Steam on alumina is probably essentially an acid reagent. Hydrogen on noble metals may stand between the pure free-radical and pure basic reagents, with more free-radical character on palladium and more basic character on platinum. Basic reagents attack ring halogens fairly readily, sometimes observing the usual order of reactivity $\mathrm{I}>\mathrm{Br}>\mathrm{Cl}>\mathrm{F}$, and sometimes reversing the order [6]. Further studies with hydrogen involving other halogenated aromatic compounds would be desirable.

\section{Experimental Procedures}

\subsection{Apparatus and Method}

Most of the hydrogenations were conducted in a train consisting of hydrogen tank, flowmeter, water or concentrated sulfuric acid bubbler, vaporizing flask, furnace tube, receiver, solid carbon dioxide trap, and water bubbler. In most experiments the hydrogen was dried, but occasionally water was delib.. erately introduced. The vaporizing flask was held at a temperature $5^{\circ}$ to $20^{\circ} \mathrm{C}$ below the boiling point of the halogen compound to be used in order to furnish a convenient partial pressure of the compound. Connections from it to the furnace tube were heated by windings of resistance wire or commercial heating tape to avoid condensation. A ball joint sealed with polychlorotrifluoroethylene grease was a convenient joint at this location. The furnace tube and subsequent parts were made of glass or copper. Glass parts were usually convenient and did not seem to interfere with the reaction in any case, but when large amounts of hydrogen fluoride were liberated the reactors were often perforated before the end of a single run and the final water bubbler was always rapidly clogged with silica derived from hydrolysis of silicon tetrafluoride. Therefore, in large-scale work involving liberation of hydrogen fluoride the furnace tube and receiver were of copper. Clogging of the final water bubbler with silica was also lessened by discharging the gas into water through an underlying layer of carbon tetrachloride. Products from the receiver were washed with water, dried, distilled, and analyzed by density, refractive index, and mass spectrometry. When hexafluorobenzene was being converted to pentafluorobenzene and other fluorinated benzenes, it was convenient to iodinate the products [7] before attempting distillation.
For hydrogen halide determinations the water washings from receiver, cold trap, and water bubbler were combined and a diluted aliquot taken. Chloride was determined by the Mohr titration, and fluoride by the thorium titration with alizarin indicator [8].

\subsection{Catalysts}

The only useful form of nickel was the commercial reagent grade powder. Unsuccessful forms included the powder mixed with glass wool; a nickel on charcoal catalyst made by soaking the charcoal in nickel nitrate, heating, and reducing; similar preparations on alumina; and also preparations on reduced copper oxide wire. The inactivity of the copper-supported catalyst was to be expected in view of well-known studies on the mechanism of catalysis. Further unsuccessful catalysts included copper, as reduced copper oxide wire, and molybdenum sulfide prepared according to Lazier [2]

Palladium on carbon was prepared by dissolving $5 \mathrm{~g}$ of palladium in aqua regia, evaporating twice with concentrated hydrochloric acid, diluting with water, pouring over $25 \mathrm{~g}$ active carbon, ${ }^{4}$ and heating with alkaline formaldehyde. The product was stored wet. Platinum on carbon was prepared in the same way, but starting from commercial chloroplatinic acid. All catalysts were reduced for several hours before using.

\subsection{Chloropentafluorobenzene Over Nickel}

The chloropentafluorobenzene consisted of several samples, boiled at $120^{\circ}$ to $125^{\circ} \mathrm{C}, \mathrm{d}_{4}^{26} 1.54$ to 1.57 , $\mathrm{n}_{\mathrm{D}}^{26} 1.4189$ to 1.4355 , obtained from the preparation of hexafluorobenzene [9, 10]. Using the general apparatus described, $24.7 \mathrm{~g}$ of chloropentafluorobenzene was placed in the vaporizer at $100^{\circ} \mathrm{C}$ and passed through a 2 - by 60 -cm furnace tube containing about $100 \mathrm{~g}$ of nickel powder in a thin layer, over a period of $3.7 \mathrm{hr}$. The collected product contained $4.48 \mathrm{~g}$ impure tetrafluorobenzene, boiled at $88^{\circ}$ to $91^{\circ} \mathrm{C}$, $\mathrm{d}_{4}^{24} 1.39, \mathrm{n}_{\mathrm{D}}^{24} 1.4105$, and $14.3 \mathrm{~g}$ recovered feed. Mass spectra indicated about 75 percent tetrafluorobenzene and 25 percent trifluorobenzene in the low-boiling fraction. The ultraviolet absorption was similar to that of known 1,2,4,5-tetrafluorobenzenes, but ultraviolet spectra do not discriminate well between the positional isomers. The low-boiling fraction probably contained the $1,2,3,5$ and $1,2,4,5$ isomers, but little of the 1,2,3,4 isomer, which is known to boil at $95^{\circ} \mathrm{C}$ [5]. Subsequent experiments produced also fractions boiling in the range $92^{\circ}$ to $98^{\circ} \mathrm{C}$, now believed to have contained 1,2,3,4-tetrafluorobenzene. After several recyclings, the chloropentafluorobenzene fraction became lower in density. It is likely that fluorine removal had occurred to produce chlorotetrafluorobenzene.

${ }^{4}$ Columbia CXAL, 4 to 8 mesh, low in copper and ash, obtained from Carbide and Carbon Chemicals Co. 


\subsection{Chloroheptafluorotoluene Over Nickel}

The 2-chloroheptafluorotoluene was a by-product of the preparation of perfluorotoluene $[9,10]$. Arrangements were as in the preceding example, except that the vaporizer bath temperature was kept at $115^{\circ} \mathrm{C}$ and the furnace temperature at $258^{\circ}$ to $285^{\circ}$ C. In many runs, a total of $1,099 \mathrm{~g}$ (4.36 moles) of chloroheptafluorotoluene yielded $85 \mathrm{~g}$ (0.39 mole) of somewhat impure heptafluorotoluene, $\mathrm{C}_{6} \mathrm{~F}_{4} \mathrm{HCF}_{3}$, boiled at $103^{\circ}$ to $112^{\circ} \mathrm{C}, 0.49$ equivalents of chloride and 0.15 equivalents of fluoride in wash waters, and $877 \mathrm{~g}$ (3.44 moles) of starting material. The aggregate time was $60 \mathrm{hr}$. The product contained several incompletely separated fractions, the larger of which are shown in table 1 . The slow decline of catalyst activity is shown in table 2 . Regeneration with water vapor was effective but only for a short time. Other arrangements of the nickel were inferior. Mixing with glass wool throughout the volume of the tube resulted in very little reaction. Attempts to pass vapor upward through a bed of powder gave poor conversions and rapid plugging. Nickel on charcoal, packed into the tube, produced an injtial heavy burst of chloride and fluoride liberation, followed by inactivity. No changes were found in the properties of recovered feed materials.

TABLE 1. Reduction products of chloroheptafluorotoluene

\begin{tabular}{|c|c|c|c|}
\hline Boiling point & Weight & Density & Refractive index \\
\hline${ }^{\circ} \mathrm{C}$ & $g$ & $d_{4}^{24}$ & $n_{\mathrm{D}}^{23}$ \\
\hline 101 to 104 & 31.6 & 1. 532 to 1.536 & 1.3753 to 1.3779 \\
\hline 105 to 108 & 15.0 & 1. 500 to 1.518 & 1.3795 to 1.3810 \\
\hline 108 to 116 & 10.4 & 1.547 & 1.3799 to 1.3802 \\
\hline
\end{tabular}

TABLE 2. Decline of catalyst activity

\begin{tabular}{|c|c|c|c|c|c|}
\hline \multirow{2}{*}{$\begin{array}{c}\begin{array}{c}\text { Cumulative } \\
\text { feed }\end{array} \\
\\
g \\
34 \\
102 \\
136\end{array}$} & \multirow{2}{*}{$\begin{array}{l}\text { Feed rate } \\
\\
\\
\qquad \begin{array}{l}g / h r \\
22.7 \\
34.5 \\
66.6\end{array}\end{array}$} & \multicolumn{2}{|c|}{$\mathrm{C}_{6} \mathrm{~F}_{4} \mathrm{HCF}_{3}$ produced } & \multicolumn{2}{|c|}{ Chloride production } \\
\hline & & $\begin{array}{c}\text { Per g feed } \\
0.136\end{array}$ & \begin{tabular}{c} 
Per hr \\
3.1 \\
\hdashline 1.7
\end{tabular} & $\begin{array}{c}m e q / g \\
0.94 \\
.53 \\
.25 \\
.39\end{array}$ & $\begin{array}{c}m e q / h r \\
21 \\
18 \\
17 \\
13\end{array}$ \\
\hline
\end{tabular}

\subsection{Chloropentafluorobenzene Over Palladium}

Chloropentafluorobenzene $9.6 \mathrm{~g}(0.0475$ mole $)$ and hydrogen $\left(100 \mathrm{~cm}^{3} / \mathrm{min}\right)$ were passed from the vaporjzer at $98^{\circ}$ to $102^{\circ} \mathrm{C}$ over $18 \mathrm{~g}$ of the palladium carbon catalyst packed in the middle section of the furnace tube, $17 \mathrm{~cm}$ by $2.5 \mathrm{~cm}$, and maintained at $285^{\circ}$ to $290^{\circ} \mathrm{C}$. The wash waters contained chloride 0.064 equivalent (theory 0.047) and 0.008 equivalent fluoride. The product, $5.5 \mathrm{~g}$, yielded the following fractions: (a) boiled at $88^{\circ}$ to $91^{\circ} \mathrm{C}, 1.23 \mathrm{~g}, \mathrm{n}_{\mathrm{D}}^{20} 1.4051$, possibly 1.2.4.5-tetrafluorobenzene and pentafluorobenzene; (b) boiled at $91^{\circ}$ to $105^{\circ} \mathrm{C}, 1.00 \mathrm{~g}, \mathrm{n}_{\mathrm{D}}^{20} 1.4021$, possibly 1,2,3,4-tetrafluorobenzene; (c) boiled at $105^{\circ}$ to $112^{\circ} \mathrm{C}, 0.5 \mathrm{~g}, \mathrm{n}_{\mathrm{D}}^{20} 1.3990$; (d) semisolid residue 2.7 $\mathrm{g}, \mathrm{n}_{\mathrm{D}}^{20} 1.3667$.

\subsection{Chloroheptafluorotoluene Over Palladium}

2-Chloroheptafluorotoluene was passed over the palladium catalyst under the same conditions as above, but using a charge of $17 \mathrm{~g}(0.0675$ mole $)$ and a vaporizer temperature of $110^{\circ} \mathrm{C}$. The time required was two hours. The wash waters yielded 0.075 equivalent chloride (theory 0.067) and 0.003 equivalent fluoride. The product contained $\alpha, \alpha, \alpha, 3,4,5,6$-heptafluorotoluene, $\mathrm{C}_{6} \mathrm{~F}_{4} \mathrm{HCF}_{3}$, boiled at $102^{\circ}$ to $105.5^{\circ} \mathrm{C}, \mathrm{n}_{\mathrm{D}}^{20.5} 1.3750$, in a yield of $11 \mathrm{~g}$ $(79.8 \%)$, and $1 \mathrm{~g}$ of residue.

\subsection{Chlorotetrafluorobenzene Over Palladium and Nickel}

1-Chloro-2,3,4,5-tetrafluorobenzene, boiled at $122^{\circ}$ to $123^{\circ} \mathrm{C}, \mathrm{d}_{4}^{24} 1.534, \mathrm{n}_{\mathrm{D}}^{24} 1.4407$, was passed over nickel and palladium catalysts under conditions summarized in table 3. A typical experiment will be described elsewhere [5]. The conversion over nickel was relatively low, but conversion and yield over palladium were very high. A total of $1,020 \mathrm{~g}$ of feed were converted over a single charge of cata-lyst without noticeable change of activity. The purest fraction of product was 1,2,3,4-tetrafluoro. benzene, boiled at $95^{\circ} \mathrm{C}, \mathrm{d}_{4}^{25.5} 1.4010, \mathrm{n}_{\mathrm{D}}^{20.2} 1.4095$.

TABLE 3. Hydrogenation of $\mathrm{C}_{6} \mathrm{~F}_{4} \mathrm{ClH}$

\begin{tabular}{|c|c|c|c|c|c|c|c|c|}
\hline \multirow{2}{*}{$\begin{array}{l}\text { Charge } \\
\text { weight }\end{array}$} & \multirow[t]{2}{*}{ Catalyst } & \multirow[t]{2}{*}{$\mathrm{H}_{2}$ flow } & \multirow[t]{2}{*}{$\begin{array}{l}\text { Vaporizer } \\
\text { tempera- } \\
\text { ture }\end{array}$} & \multirow[t]{2}{*}{$\begin{array}{l}\text { Furnace } \\
\text { tempera- } \\
\text { ture }\end{array}$} & \multirow[t]{2}{*}{ Rate } & \multirow{2}{*}{$\begin{array}{l}\text { Yield } \\
\mathrm{C}_{6} \mathrm{~F}_{4} \mathrm{H}_{2}\end{array}$} & \multicolumn{2}{|c|}{$\begin{array}{l}\text { Halogen removed, } \\
\text { equivalents per mole } \\
\text { of feed }\end{array}$} \\
\hline & & & & & & & $\mathrm{Cl}^{-}$ & $\mathrm{F}^{-}$ \\
\hline \begin{tabular}{r}
\multicolumn{1}{c}{$g$} \\
15 \\
123.5 \\
92.4 \\
117.5 \\
123.2
\end{tabular} & $\begin{array}{l}\text { Ni powder } \\
20 \mathrm{~g} \mathrm{Pd}, \mathrm{Ca} \\
\text { do } \\
\text { do } \\
\text { do }\end{array}$ & $\begin{array}{c}\mathrm{cm}^{3} / \mathrm{min} \\
50 \\
100 \\
100 \\
100 \\
100\end{array}$ & $\begin{array}{r}\circ C \\
80 \\
108 \\
108 \\
108 \\
108\end{array}$ & $\begin{array}{l}{ }^{\circ} C \\
277 \\
280 \\
280 \\
280 \\
280\end{array}$ & $\begin{array}{c}g / \min \\
0.2 \\
.54 \\
.54 \\
.54 \\
.54\end{array}$ & $\begin{array}{l}\% \\
12 \\
77.2 \\
87.5 \\
84 \\
78.2\end{array}$ & $\begin{array}{l}\quad \% \\
32 \\
77 \\
90.8 \\
77 \\
73\end{array}$ & $\begin{array}{rl} & \% \\
\sim & 1 \\
>1 \\
& 2.8 \\
>1 & 1\end{array}$ \\
\hline
\end{tabular}

a $1 / 8$ in. $\mathrm{C}$ pellets. 


\subsection{Hexafluorobenzene Over Palladium and Platinum}

Hexafluorobenzene, $\mathrm{C}_{6} \mathrm{~F}_{6}$, was passed over the palladium and platinum catalysts under conditions detailed in table 4 . Runs are numbered in the order performed to illustrate cumulative effects. As the product was very incompletely separated by fractional distillation (table 5) the progress of reaction was routinely gauged by ionic fluoride liberated. The product from one run over palladium boiled at $82^{\circ}$ to $86^{\circ} \mathrm{C}$, had a refraction index $\mathrm{n}_{\mathrm{D}}^{2.65} 1.3870$, and according to mass spectrographic analysis con- sisted of 45 percent $\mathrm{C}_{6} \mathrm{~F}_{6}, 40$ percent $\mathrm{C}_{6} \mathrm{~F}_{5} \mathrm{H}, 10$ percent $\mathrm{C}_{6} \mathrm{~F}_{4} \mathrm{H}_{2}, 4$ percent $\mathrm{C}_{6} \mathrm{~F}_{3} \mathrm{H}_{3}$, and 1 percent $\mathrm{C}_{6} \mathrm{~F}_{2} \mathrm{H}_{4}$. A run preceding No. 1 showed no fluoride removed from $\mathrm{C}_{6} \mathrm{~F}_{6}$ over palladium at $270^{\circ} \mathrm{C}$, and one following No. 2 showed that the palladium catalyst had lost all its activity after that run at $325^{\circ} \mathrm{C}$. The platinum catalyst declined much more slowly (runs 7 to 9). Catalyst activity had diminished to perhaps $2 / 3$ of original activity after $950 \mathrm{~g}$ of feed had been processed. The platinum catalyst was inactive at $250^{\circ} \mathrm{C}$ and had an optimum temperature near $300^{\circ} \mathrm{C}$ (runs 5, 6, and 7). There was an initial period of lower activity (runs 3 and 4).

TABLE 4. Hydrogenation of hexafuorobenzene $\mathrm{C}_{6} \mathrm{~F}_{6} \stackrel{\mathrm{H}_{2}}{\longrightarrow} \mathrm{C}_{6} \mathrm{~F}_{5} \mathrm{H}, \mathrm{C}_{6} \mathrm{~F}_{4} \mathrm{H}_{2}, \mathrm{C}_{6} \mathrm{~F}_{3} \mathrm{H}_{3}$, etc.

\begin{tabular}{|c|c|c|c|c|c|c|c|c|}
\hline Run & $\begin{array}{l}\text { Charge } \\
\text { weight }\end{array}$ & Time & Catalyst & $\mathrm{H}_{2}$ flow & $\begin{array}{l}\text { Vaporizer } \\
\text { tempera- } \\
\text { ture }\end{array}$ & $\begin{array}{l}\text { Furnace } \\
\text { tempera- } \\
\text { ture }\end{array}$ & $\begin{array}{l}\text { Weight } \\
\text { recovered }\end{array}$ & $\begin{array}{l}\mathrm{F}-\text { re- } \\
\text { moved, } \\
\text { equivalents } \\
\text { per mole } \\
\text { of feed }\end{array}$ \\
\hline $\begin{array}{l}1 \\
2 \\
3 \\
4 \\
5\end{array}$ & $\begin{array}{c}g \\
17.6 \\
17.6 \\
48 \\
38.6 \\
150\end{array}$ & $\begin{array}{c}h r \\
\sim_{2}^{2} \\
\sim_{2.7} \\
2.5 \\
2.0\end{array}$ & 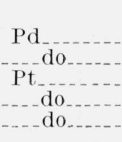 & $\begin{array}{c}\mathrm{cm} 3 / \mathrm{min} \\
100 \\
100 \\
50 \text { to } 100 \\
75 \text { to } 100 \\
100 \text { to } 125\end{array}$ & $\begin{array}{l}{ }^{\circ} C \\
\sim 60 \\
\sim 60 \\
\quad 70 \\
70 \\
70\end{array}$ & $\begin{array}{c}{ }^{\circ} C \\
300 \\
325 \\
300 \\
300 \\
280\end{array}$ & $\begin{array}{c}g \\
12.5 \\
? \\
45 \\
33 \\
\end{array}$ & $\begin{array}{l}\% \\
17 \\
98 \\
17 \\
36 \\
58\end{array}$ \\
\hline $\begin{array}{l}6 \\
7 \\
8 \\
9\end{array}$ & $\begin{array}{l}130 \\
207 \\
247 \\
136\end{array}$ & $\begin{array}{l}1.7 \\
5.5 \\
6 \\
3.5\end{array}$ & \begin{tabular}{l}
$\ldots$ do \\
\hdashline do... \\
\hdashline do \\
\hdashline do
\end{tabular} & $\begin{array}{c}100 \text { to } 125 \\
50 \\
50 \\
50 \text { to } 100\end{array}$ & $\begin{array}{l}70 \\
70 \\
70 \\
70\end{array}$ & $\begin{array}{l}250 \\
300 \\
300 \\
300\end{array}$ & $\begin{array}{l}214 \\
117\end{array}$ & $\begin{array}{r}0 \\
63 \\
50 \\
44\end{array}$ \\
\hline
\end{tabular}

TABLE 5. Products from $\mathrm{C}_{6} \mathrm{~F}_{6}+\mathrm{H}_{2}$

\begin{tabular}{|c|c|c|c|c|}
\hline Boiling point $\ldots \ldots$ & 80 to 82 & 82 to 84.5 & 84.5 to 90 & $>90$ \\
\hline Specific gravity $\ldots \ldots \ldots \ldots \mathrm{d}_{4}^{24.6}$ & 1. 5273 & 1.5075 & 1.4336 & 1.3018 \\
\hline Refractive index $\ldots \ldots \ldots n_{D}^{20}$ & 1. 3871 & 1. 3910 & 1.4015 & 1.4112 \\
\hline Weight_... ................... & 157 & & & 8 \\
\hline Mass spectrometric analysis: & & & & \\
\hline $\mathrm{C}_{6} \mathrm{~F}_{6} \ldots \ldots$ mole $\%$ & 73. 2 & Lost & 22. 2 & 6.8 \\
\hline _._._. mole \% & 15.9 & _._do do... & 27.3 & 46.2 \\
\hline .......mole \% & 6.2 & _._. do _... & 24.8 & 34.0 \\
\hline $\mathrm{C}_{6} \mathrm{~F}_{3} \mathrm{H}_{3} \ldots \ldots$ & 3.1 & ... do ... & 15.8 & 12.2 \\
\hline Lower F _._._._._._. mole \% & 1.6 & $\ldots$ do ..... & 9.9 & 0.8 \\
\hline
\end{tabular}

Washington, December 11, 1958.

\section{References}

[1] P. Sabatier and A. Mailhe, Compt. rend. 138, 245 (1904).

[2] H. R. Arnold, and W. A. Lazier, U.S. Patent 2,025,032.

[3] F. Swarts, Acad. roy. Belg. Classe sci. [5]6, 399 (1920).

[4] N. V. Sidgwick, The Chemical Elements and Their Compounds, vol. 1, p. 122, Oxford, Clarendon Press, 1950.

[5] W. J. Pummer, R. E. Florin, and L. A. Wall, J. Research NBS 62, (1959) RP2939.

[6] J. F. Burnnett and T. K. Brotherton, J. Am. Chem. Soc. 78, 155 (1956).

[7] M. Hellmann, A. J. Bilbo, and W. J. Pummer, J. Am. Chem. Soc. $7 \%, 3650$ (1955).

[8] E. Rinck, Bull. soc. chem. France 1948, 305.

[9] E. T. McBee, V. V. Lindgren, and W. B. Ligett, Ind. Eng. Chem. 39, 378 (1947).

[10] R. E. Florin, L. Wall, and W. J. Pummer, J. Research NBS 62, (1959) RP2938. 